\title{
A lesbianidade como arte da produção de si e suas interfaces no currículo*
}

\author{
PATRÍCIA DANIELA MACIEL \\ Instituto Federal do Paraná, Colombo, PR, Brasil \\ MARIA MANUELA ALVES GARCIA \\ Universidade Federal de Pelotas, Pelotas, RS, Brasil
}

\section{RESUMO}

Com base em relatos autobiográficos de um grupo de sete mulheres professoras da educação básica que em algum momento assumiram-se lésbicas, discute-se, valendo-se de discursos de gênero, como elas produzem a docência e o currículo. Como referências, utiliza-se a noção de experiência de Walter Benjamin, Giorgio Agamben e Jorge Larrosa, que inspirou a coleta e a análise das narrativas. Aliam-se a esses estudos as contribuições de Michel Foucault acerca da sexualidade e do cuidado de si e a crítica de Judith Butler ao sistema corpo/sexo/gênero. Conclui-se que as experiências das professoras como lésbicas nas escolas produzem uma pedagogia que atua não apenas como questionamento dos padrões heteronormativos, mas como uma produção de conhecimento próprio pela qual elas reinventam suas identidades como professoras.

\section{PALAVRAS-CHAVE}

currículo; gênero; professoras lésbicas.

* Texto apresentado na 37a Reunião Nacional da Associação Nacional de Pós-Graduação e Pesquisa em Educação (ANPEd), em 2015, no Grupo de Trabalho 12 "Currículo". Disponível em: <http://37reuniao.anped.org.br/trabalhos/>. Acesso em: 23 jan. 2018. 


\title{
THE LESBIANISM AS PRODUCTION ART OF ONESELF AND THEIR INTERFACES IN THE CURRICULUM
}

\begin{abstract}
The autobiographical accounts of a group of seven women and primary school teachers who, at some time in their lives, came out as lesbians, were used to discuss how these women create a curriculum based on gender discourses. As references, we used the notion of the experiences of Walter Benjamin, Giorgio Agamben and Jorge Larrosa, who inspired the collection and analysis of the narratives obtained. In addition to the referred studies, the contributions of Michel Foucault on sexuality and self-care, and Judith Butler's critique of the body/sex/gender structure were also considered. It was concluded that the experience of these teachers as lesbians in schools produces a pedagogy that does not merely question the heteronormative standards, but also produces its own knowledge through which they reinvent their identities as teachers.
\end{abstract}

KEYWORDS

curriculum; gender; lesbian teachers.

\section{EL LESBIANISMO COMO ARTE DE LA PRODUCCIÓN DE SI Y SUS INTERFACES EN EL CURRÍCULO}

\section{RESUMEN}

Basado en relatos autobiográficos de un grupo de siete mujeres docentes de la educación básica y que, en algún momento de sus vidas, si asumen como lesbianas, se discute como esas mujeres, a partir de los discursos de género, producen la docencia y el plan de estudios. Como referencias, se utiliza el concepto de experiencia de Walter Benjamin, Giorgio Agamben y Jorge Larrosa, que inspiró la búsqueda y análisis de los relatos. Junto a estos estudios, las contribuciones de Michel Foucault sobre la sexualidad y el cuidado de sí mismos, y la crítica de Judith Butler al sistema de cuerpo/sexo/género. Se concluye que las experiencias de las profesoras como lesbianas en las escuelas produce una pedagogía que actúa no sólo como cuestionamiento de los patrones heteronormativos, sino como una producción de conocimiento proprio por la que reinventan su identidad como maestras.

PALABRAS CLAVE

currículo; género; profesoras lesbianas. 
Os estudos acadêmicos publicados no Brasil que relacionam gênero e currículo, nos últimos quinze anos, ${ }^{1}$ apresentam-se voltados em grande parte para as análises dos efeitos dos discursos de gênero no currículo das instituições educacionais. Utilizando, em sua maioria, uma perspectiva teórica pós-estruturalista com vertentes dos estudos culturais, feministas e queer, esses trabalhos têm mostrado, com diferentes objetos de análise e sujeitos de pesquisa, que os processos de subjetivação dos sujeitos, assim como o currículo, têm sido constituídos nos espaços educativos em uma relação de disputas e conflitos advindos das várias circunstâncias culturais.

Esses estudos enfatizam que os discursos de gênero no currículo vêm, por vezes, reiterando a maximização das diferenças entre os sexos, entre os homens e as mulheres, e por outras, em menor escala, problematizando, valendo-se de algumas estratégias políticas e/ou pedagógicas, a desconfiguração dessas linhas identitárias no campo educacional. Com uma contribuição importante para os estudiosos do campo curricular e da educação, essas investigações afirmam que os discursos de gênero, ao problematizarem os processos de produção de significação dos corpos e das sexualidades, não apenas desmoronam e interferem na repetição de algumas verdades e pedagogias relativas às identidades sexuais heteronormativas, mas também polemizam e explodem o próprio raciocínio do campo curricular como uma corporificação objetiva de conhecimentos.

O que interessantemente esses autores e autoras dizem é que, como fenômeno discursivo e cultural, o gênero, ao subordinar-se aos padrões hegemônicos da cultura normativa da escola e, ao mesmo tempo, resistir e abandonar a concepção de ser humano imutável em relação ao sexo, não apenas opera nos processos de normalização e de resistência no que concerne ao gênero. Opera também como uma tecnologia que contribui para que a pedagogia e o currículo sejam vistos como um conjunto de conhecimentos cuja construção é provisória, circunstanciada e subjetiva.

Esses estudos, portanto, vêm fazendo um movimento de questionamento das relações entre a produção das identidades e a significação do próprio currículo. De outra maneira, eles vêm entendendo que, irremediavelmente, o currículo é marcado pelos processos discursivos de formação do gênero dos sujeitos. No que tange à produção da identidade docente, o que as pesquisas mais recentes enfatizam é o poder dos discursos de gênero dos professores, que protagonizam ou problematizam as questões dos sujeitos gays, lésbicas, travestis, transexuais, transgêneros e queers ${ }^{2}$ na transformação do campo curricular.

Como se pode perceber, há um anseio de parte de um grupo de pesquisadores que tratam da relação entre currículo e gênero, como Vianna e Unbehaum (2006),

1 Levantamento realizado com base nas publicações indexadas no banco de dados SciELO (www.scielo.br) com os descritores gênero e currículo, entre os anos de 2001 e 2014. Foram analisados 17 artigos, em nove periódicos: Revista de Estudos Feministas, Pró-Posições, Educação e Revista, Revista Brasileira de Ciências do Esporte, Revista Brasileira de Enfermagem, Educação e Pesquisa, Educação Ẽ Sociedade, Educação e Realidade e Cadernos de Pesquisa.

2 Sujeito queer, de acordo com Louro (2008), é o sujeito da sexualidade desviante, como homossexuais, bissexuais, transexuais, travestis, drags. 
Reis e Paraíso (2014) e Furlani (2007), por análises que articulam essas temáticas a fim de refletir sobre o impacto das pedagogias que buscam analisar a intervenção crítica das relações de gênero no ensino. Nesse contexto, nossa proposta é analisar algumas práticas subversivas, alguns indícios de pedagogias que podem ser consideradas queer. ${ }^{3}$ Abordamos como os discursos de gênero interpelam as professoras que agem segundo uma política de gênero marginal no território do natural e do real e como a desconstrução dos princípios que regem a normalização do gênero, ao fazer parte da escola, cria a possibilidade de suspeita do modo como foram selecionados e escolhidos determinados saberes a serem ensinados e não outros. Mais especificamente, analisamos como o meio discursivo/cultural dos discursos da lesbianidade - nos quais a estabilidade da estrutura binária do sexo é subvertida, as categorias das identidades são abertas e a política da identidade sexual é compreendida como produção política e cultural — possibilita o protagonismo de experiências e pedagogias próprias de professoras com a experiência de homoafetividade.

Este artigo baseia-se em uma tese de doutorado (Maciel, 2014) que tratou do tema gênero e sexualidade no magistério valendo-se de narrativas de um grupo de sete professoras que se assumiram lésbicas em algum momento ou etapa de sua vida. É parte de uma investigação que teve como foco os modos singulares de um grupo de professoras lésbicas de viver o gênero e o feminino na docência, em meio a uma cultura fortemente heteronormativa e disciplinar. Assim, o que ora apresentamos é um recorte desse estudo no qual evidenciamos como as professoras pesquisadas foram subjetivadas pelos discursos de gênero e como foram afetadas por essas experiências a ponto de transformarem a si e a suas ações como professoras. Nosso objetivo é mostrar como as experiências de gênero das mulheres investigadas constituíram um conhecimento próprio e uma mediação das situações vividas por elas como professoras nas escolas e como problematizaram a essencialização das identidades sexuais e a heterossexualização dos conteúdos e práticas escolares.

A pesquisa utilizou como referencial analítico os discursos de gênero e sexualidade tomando como base uma perspectiva pós-estruturalista e pós-identitária representada pelos estudos de autores como Michel Foucault, Judith Butler, Linda Nicholson, Teresa de Lauretis, Susanne Luhmann, Guacira Lopes Louro e outros. Autores estes que entendem o sexo e o gênero como discursos de poder, convenções culturais e normas que são construídas socialmente, ou seja, autores que negam veementemente o primado biológico que, representado pela genitália, cria uma identidade fixa para os sujeitos.

A investigação contou com professoras que foram entrevistadas durante o ano de 2012, selecionadas a partir de dois critérios:

1. ter atuado ou estar atuando naquela data como professora de educação básica;

2. ter assumido a posição de lésbica em algum momento de sua vida.

Dentro desse quadro, resultaram as histórias de sete mulheres na faixa etária de 30 a 56 anos, naturais de cidades do Rio Grande do Sul, formadas em univer-

3 Queer está sendo entendido como um jeito de pensar e de estar que não inspira um centro, uma identidade, mas como um jeito de desafiar aquilo que é entendido como norma regulatória (Louro, 2008). 
sidades do mesmo estado em cursos de bacharelado e licenciatura em artes visuais, direito, letras, educação física e história, e também em cursos de pós-graduação em educação - especialização, mestrado e doutorado - e com tempo de magistério que variava de 6 meses a 33 anos.

A coleta de dados teve como inspiração e base teórica a história oral e o método biográfico seguindo as reflexões de Benjamin (1983,1996), Agamben (2008) e Larrosa (2010), autores que entendem a narrativa e a memória não como um processo linear de busca de algo que se passou no intuito de produzir uma história e/ou um conhecimento com verossimilhança em relação ao passado. A narrativa autobiográfica é antes entendida como um processo incompleto, de distração, de recusa do armazenamento, de negação, de esquecimento, de fantasia e tantos outros aspectos em que os sujeitos criam, à medida que narram, a verdade dos fatos e a experiência de si.

A análise, portanto, utilizou-se da experiência do contar das professoras como um conhecimento que elas produziram de si no momento das entrevistas (Benjamin,1983,1996), como uma prática discursiva, uma possibilidade que tiveram para falar e produzir a si mesmas (Agamben, 2008) e, ainda, como o lugar onde puderam refazer suas histórias (Larrosa, 2010). Em outras palavras, realizou-se uma análise em que as entrevistas foram tratadas como uma experiência de si, em que as professoras puderam criar versões de si e dar sentidos aos acontecimentos de suas vidas, como uma "figura porvir"(Larrosa, 2010), como um sentido que foi produzido sobre o que se passou. O que trazemos, portanto, são histórias de professoras que podem ser contadas como experiências que se dão na relação delas com o mundo.

Considerando essas questões gerais, propomos, na primeira parte do texto, a discussão dos conceitos de gênero e currículo. Tratamos nessa parte do artigo do gênero e do currículo como artefatos na produção de si e dos outros no campo educacional. Discutimos também a contribuição da pedagogia queer para a decomposição da centralidade da produção de sentidos e conhecimentos a partir do pensamento binário homem/mulher, heterossexual/homossexual, pensamento este instituído pela cultura ocidental. Posteriormente, exploramos como as professoras lésbicas, no exercício de suas decisões circunstanciadas, não apenas produzem a si nas escolas como docentes, mas também produzem ações e práticas que revelam o efeito do não saber de alguns conhecimentos nos espaços educacionais. Por último, como tentativa de fechamento, pensando o gênero e o currículo como dimensões políticas, defendemos que as professoras analisadas são protagonistas importantes na produção curricular e na constituição de uma pedagogia da alteridade.

\section{GÊNERO, CURRÍCULO E PEDAGOGIA QUEER}

Pensar uma conexão entre o gênero e o currículo traz questões e problemas. A primeira questão é como não cair na figura do currículo como objeto tradicional, como uma descrição de conhecimentos básicos e tão familiares aos professores? Daí em diante, as questões se multiplicam: Como ousar e tomar distanciamento para estranhar as atividades de ensino tão rotineiras? Como selecionar, ao mesmo tempo, as práticas entediantes e excitantes dos professores? Como, além disso, explicar os caminhos que os professores tomam no ato de ensinar e que nos permitem chegar a 
uma compreensão ampliada das diversas questões que atravessam suas práticas nos currículos, entre elas a de gênero? Como descrever o currículo e o próprio sujeito entendido como subjetivação - como a constituição de um projeto inconcluso, como um caminho discursivo repleto de paixões e desvios? Como perceber e analisar o limiar, os estados intermediários, o entre-lugar, a fronteira, as lutas e os estados de repouso dos discursos de gênero como contextos de produção do campo curricular? Como seria a pedagogia queer na escola? Onde ela se daria e para quem?

Tantas questões, por vezes, levam-nos a uma postura paralisante. É difícil decifrar os enigmas, os efeitos das características identitárias nos aspectos de produção dos professores e do currículo. Principalmente porque são raras as experiências em que os sujeitos produzem uma relação com a verdade, uma verdade que eles produzem não apenas em suas relações com as leis ou regras, mas pela soberania do próprio sujeito sobre si. É difícil captar as experiências imediatas dos sujeitos, suas condutas, segundo suas verdades éticas e individuais. É difícil encontrar relatos que elucidam e explicam as conformidades das condutas dos sujeitos com as suas próprias verdades.

Pois bem, utilizamos os discursos de gênero neste texto para mostrar exatamente essa vontade de pensar o currículo não apenas como uma tecnologia de regulação e limitação do conhecimento advindo das práticas e princípios de governamento, mas também como uma tecnologia de regulação que se constitui a partir das manifestações das verdades produzidas nas relações dos sujeitos consigo mesmos e com os outros, quando esses cuidam de si próprios, quando se ocupam de si mesmos na relação com os outros.

É importante dizer que temos a preocupação epistemológica e política de pensar o currículo não apenas como um projeto de conhecimento selecionado tomando como base uma cultura mais ampla para ser ensinado a todos, mas como um dispositivo que, ao mesmo tempo, é constituído e instituinte de saberes e poderes. Entendemos o currículo como uma tecnologia, uma estratégia de produção de saberes que envolve não apenas conhecimentos, mas os sujeitos em suas diferentes formas de trabalho ético e estético. Entendemos o currículo como a produção de saberes atravessada por tensões que resultam dos embates entre mecanismos de regulações externos presentes no cotidiano do trabalho escolar e por forças que apontam para a invenção de si mesmo e do mundo.

Visto por essa perspectiva, salientamos a coexistência de práticas curriculares e discursivas hegemônicas atravessadas pela oposição homem e mulher, heterossexual e homossexual, que marca a centralidade da naturalização dos corpos dos sujeitos na escola, e de práticas curriculares e discursivas que lutam pela legimitidade da multiplicidade dos modos de viver o corpo e a sexualidade. O que apresentamos são algumas pistas do enfrentamento das professoras lésbicas na crítica a uma perspectiva curricular que tem como base os ideais regulatórios da heterossexualidade, de uma pedagogia que delega os sujeitos homossexuais para o campo do abjeto e do estranho, e até mesmo o do patológico. O que mostramos são alguns fragmentos de um currículo produzido por outras formas de existência e experiências de gênero e sexo que escapam ao que é considerado normal e certo. Um currículo feito baseado em práticas regulatórias que mostram positivamente outras possibilidades de articulações culturais. Trata-se na 
verdade de um currículo que radicaliza alguns ideais que legitimam a normalidade, do reconhecimento de práticas que possibilitam aos sujeitos rearticulações e linhas de fuga dentro da escola.

Para traduzir a potência da homossexualidade feminina, usamos, portanto, o depoimento das professoras lésbicas. Para mostrar como os sujeitos ditos marginais minam a estabilidade de uma pedagogia convencional, tornamos conhecíveis as histórias dessas mulheres não para mostrar como as lésbicas são representadas nos currículos estabelecidos, mas para mostrar como elas, na ausência de um conhecimento sobre sua vida na educação, levantam questões sobre o saber/conhecer na sala de aula.

O gênero é suposto aqui em acordo com o pensamento de feministas como Butler (2010), Nicholson (2000), Lauretis (1994), Preciado (2005, 2014) e Louro (2008). O gênero e o sexo não são atributos naturais, mas mecanismos discursivos e de poder pelo qual o sexo passa a definir aquilo que somos. Usamos os discursos do gênero como um caminho para analisar como as professoras lésbicas pensam em relação a si mesmas nas escolas e como, por meio da própria vigilância em torno de si, agem e passam a vida como docentes. E a partir do gênero, portanto, que procuramos entender como essas mulheres se interrogam sobre o sexo na escola, como tomam esse tema como uma preocupação no âmbito escolar, como se produzem enquanto docentes na relação com seus alunos e colegas, considerando seus desejos e saberes.

Concordamos, portanto, que é preciso ter o gênero como um campo de referência para compreender o currículo e o próprio campo pedagógico. De acordo com Louro (2000), é preciso pensar a ambiguidade, a multiplicidade e a fluidez das identidades sexuais e de gênero porque elas nos sugerem não apenas a crítica da lógica binária entre homens e mulheres, masculino e feminino, heterossexual e homossexual, mas também novas formas de pensar a cultura, o conhecimento, o poder e a educação.

No âmbito dessas discussões, entendemos que as falas das professoras lésbicas sobre suas práticas pedagógicas nas escolas expressam não apenas a reinscrição e a crítica dos saberes de uma heterossexualidade compulsória (Butler, 2010; Rich, 2010) no currículo, mas também a criação de uma pedagogia que funciona mediante o questionamento da materialidade dos corpos e da sexualidade. De acordo com Preciado (2014, p. 23), "é hora de deixar de estudar e de descrever o sexo como parte da história natural das sociedades humanas", é hora de explorarmos e mostrar que a natureza não é senão uma negociação permanente das tecnologias que modificam corpos, sujeitos e as próprias instituições. Parafraseando a autora, é hora de repensarmos as determinações dos discursos de gênero de identidades fixas e de invocar as iniciativas de desconstrução da superioridade dos saberes biológicos e políticos da dominação masculina. É o momento de desenvolvermos conhecimentos de uma pedagogia contrassexual, de radicalizar o sexo e o gênero.

Para mostrar como são maximizados alguns discursos contrassexuais na escola, utilizamos as falas das entrevistadas valendo-nos de um movimento analítico que utiliza o conceito de cuidado de si, de Foucault (2004), em que os relatos foram lidos como indicativos dos modos como as professoras operam com as verdades que elas criam para si a partir de suas experiências como lésbicas. Usamos essa noção para indicar como, ao fazer uso de determinadas práticas e discursos de gênero, elas 
constituíram alguns modos de ser como docentes. O cuidado de si é entendido como um trabalho ético e/ou uma elaboração que as professoras pesquisadas realizaram sobre si próprias e sobre os outros, na mediação que fizeram entre si e os discursos de gênero (o que está fora, exterior) para atuarem como docentes. A noção do cuidado de si faz referência, neste estudo, a uma relação que as entrevistadas tiveram consigo mesmas para construir, dentro dos códigos de controle da sexualidade, algumas maneiras próprias de produzir modos docentes na relação consigo e com os outros, sejam alunos ou outros agentes na escola.

Para compreender como as experiências de gênero das professoras pesquisadas tornaram-se uma prática de reflexão, de ascese, ou seja, uma prática de produção de si, em que passaram a refletir sobre si como lésbicas em relação ao mundo e à docência, retomamos algumas partes dos relatos em que elas, ao exporem o modo como experienciaram o gênero, davam sentido a essas experiências.

Procuramos evidenciar os discursos em que as professoras contam como foram arrebatadas pelo gênero, como foram afetadas por essas experiências e transformaram a si e as suas ações como professoras, de um modo único e singular, a partir de situações de suas próprias vidas. Apresentamos, com isso, uma tentativa de pensar como elas usam o gênero como um "principio de alteridad"(Larrosa, 2005), ou seja, como usam o conhecimento de gênero, que elas construíram como próprio, como um processo subjetivo com o qual refletem e pensam as situações da vida, do cotidiano, do presente, inclusive como professoras nas escolas. A pergunta que resta, então, é: De que forma os modos de viver, pensar e de contar-se, com base no gênero, tornaram-se modos de experienciar, pensar e ver-se como docentes?

Mesmo que isso possa representar uma virada pragmática, ou seja, uma tentativa de entender, por meio da narrativa das professoras lésbicas, como elas tratam o gênero em situações de sala de aula e da escola, queremos registrar que nossa intenção ao recorrer às histórias dessas professoras não foi compreender como elas transformam suas experiências de vida em conhecimentos/conteúdos e/ou práticas pedagógicas. Essa hipótese foi negada pelas entrevistadas quando muitas afirmaram que a condição de lésbicas sequer lhes propiciou o conhecimento necessário para tratar a diversidade sexual e a homossexualidade na sala de aula e, também, quando enfatizaram que conseguiram tratar de gênero e sexualidade na escola após concluírem uma formação pedagógica específica para trabalhar com o tema. A intenção é problematizar como o gênero tornou-se um domínio subjetivo e material (a experiência de gênero como um acontecimento) na vida das participantes da pesquisa. Queremos mostrar como o gênero pode ser considerado, em suas experiências de professora, um dos operadores pelo qual elas constituem suas referências para agir como docentes. $\mathrm{O}$ que queremos salientar é a complexidade da formação da subjetividade dessas professoras com base no gênero. É mostrar as diversas formas como o gênero pode aparecer na vida delas.

Partimos do princípio de que o gênero tem efeito na educação e na escola. Tem efeito sobre o modo como os professores, em geral, atuam e ensinam nas escolas. Avançando nessa reflexão, pensamos que as experiências de vida dessas professoras têm um efeito transformador na escola quando elas passam a agir levando em conta a releitura de sua vida como lésbicas, quando aprofundam a 
noção de si com base no gênero, quando ressignificam essas experiências, quando transformam, em sua biografia, os modos de pensar e agir como professoras. Nossa intenção, então, é falar dessas experiências de um modo particular; da experiência de gênero como um domínio, um campo de conhecimento que elas usam para agir como professoras.

Discutiremos, ao longo deste ensaio, as relações entre a forma como as professoras exploram suas sexualidades e, cautelosamente, apresentaremos alguns indícios do modo como acontece a produção de uma pedagogia queer. De forma mais geral, procuraremos mostrar que existe uma relação direta entre o gênero e a forma de as professoras explorarem suas subjetividades na sala de aula. Que elas não organizam, necessariamente, um ou mais conteúdos de gênero para ser ensinado, mas que há a interferência do gênero no modo como elas tornam inteligíveis os conhecimentos. Mesmo que em escassos exemplos, percebemos que há uma pedagogia, não previsível, um determinado tipo de currículo que passa a ser operado a partir da visibilidade e da experiência do corpo engendrado das professoras pesquisadas. É possível dizer que há um contraconhecimento (Luhmann, 1998), que há tecnologias de resistência sexuais, contradisciplinamentos sexuais (Preciado, 2014), técnicas adotadas pelas professoras voltadas para produzir tipos específicos de atitudes pessoais, comportamentos e hábitos dos estudantes nas escolas, uma episteme, que sinaliza, como nos ensina Sedgwick (1990), a falência do termo hetero/ homo, a falência do próprio constructo universal de homem/mulher e de tudo que insistentemente se coloca como certeza.

De acordo com Louro (2001, p. 542), as chamadas "minorias sexuais", na década anterior, já eram "muito mais visíveis" do que antes, o que vem gerando um movimento de ruptura não apenas na forma de o sujeito assumir o gênero, de compreender os papéis, as práticas sexuais e as regulações inscritas nos corpos, mas no modo de ele relacionar-se com o "saber-prazer" (Preciado, 2014). Hoje encontramos grupos que radicalizam não apenas o corpo, mas que hibridizam as linguagens na própria lei e nas instituições políticas e sociais, o que gera efeito irreversível na maneira de os sujeitos compreenderem a (des)naturalização do gênero, da raça, da classe, por exemplo.

Nesse sentido, o estado de lesbianidade das professoras não é apenas entendido como um referente da verdade do eu, mas é um movimento sexual radical quando estas inventam seus próprios modos de falar sobre si e sobre o que pensam do mundo no processo de ensino e aprendizagem. Vale ressaltar que a pedagogia de gênero identificada na fala das professoras não pode ser situada como um modelo de ensino, como uma técnica que sistematiza conhecimentos e disciplinas a serem adotados na instrução ou como um processo de decifração da razão. Essa pedagogia é antes um resíduo que constitui o ponto de fuga, de divergência da repetição, de fecundação, de criatividade para grupos que não se permitem sujeitados pelos códigos convencionais.

O que queremos destacar é que os discursos de gênero demandam uma autorreflexividade do campo pedagógico, que a educação precisa pensar os discursos do sexo no campo pedagógico como uma via de transformação do arcabouço discursivo daquilo que nos prende como sujeitos. 
Enfim, queremos pensar os discursos do gênero na escola não apenas como um campo de ação em que os atos dos professores são entendidos e reduzidos às regras e normalizações vinculadas aos valores e às leis institucionais/governamentais, mas como ação/efeito em que os sujeitos vinculam-se também, ou não, aos códigos da cultura, em que fazem combinações, composições, adaptações e derivações em seus modos próprios de reagir e produzir a si.

\section{A LESBIANIDADE COMO EXPERIÊNCIA E PRODUÇÃO DE SI}

Serão apresentados, neste item, alguns fragmentos das entrevistas em que as professoras perceberam a si mesmas como lésbicas na escola, momentos nos quais prestaram atenção aos próprios movimentos enquanto mulheres engendradas (Lauretis, 1994), em que escutaram a si mesmas e responderam segundo suas experiências. Tratamos o conhecimento aqui como uma prática parresiasta, de autoformação, de algo que se produz na existência do sujeito e na atividade docente, em uma relação de diagnóstico com o próprio corpo e, quase sempre, em um trabalho de enfrentamento e despreendimento de si.

Os depoimentos das professoras falam de experiências em que o conhecimento é produzido valendo-se dos movimentos de reflexão que as professoras fazem de si mesmas enquanto seres genereficados e engendrados na docência, na relação consigo e com os outros. Falam da presença de seus corpos, que cruzam fronteiras de gênero na escola, subvertem condutas sexistas e afirmam outras possibilidades de existência, instituindo de qualquer modo uma pedagogia.

O que apresentamos é a constituição de um conjunto de falas em que elas (re)significam suas posições como professoras pelas interpretações que têm de suas experiências de gênero. Algumas situações das entrevistas são exercícios de reflexividade que indicam a construção de saberes e de saberes sobre si que mantêm as professoras vivas, por suas particularidades, dentro dos espaços/ambientes marcados fortemente pela ortopedia pan-óptica.

Para iniciar falando do modo como as professoras entrevistadas citam como estabelecem no currículo algumas experiências com seus próprios sistemas de valores, apontamos a noção de experiência usada na narrativa da professora Bruna, que reconhece o fato de ser lésbica como um princípio, uma lógica de ação e de reflexão para ver o mundo. Nas palavras de Bruna:

[...] de repente o fato de tu ser gay, ser lésbica ou ser trans, o fato de tu não ser heterossexual te faça tu ter toda uma outra compreensão de mundo, que é uma compreensão de quem está sendo achacado, de quem não pode se beijar na esquina, de quem não pode; então tu não vai fazer isso com os outros em outras fases da tua vida, teoricamente [...]. (Bruna, 2012)

Bruna indica que a lesbianidade tem uma significação em sua vida e traz um exemplo do que isso significa para ela, a ponto de guiar sua conduta. Ela usa o fato de ser "achacada" como uma lição de vida. Ela objetiva o seu pensamento levando em conta essas situações de negação e privação e, a partir dessa experiência, 
define a forma como deve agir em relação aos outros. Usa essa experiência como um conhecimento positivo em relação a si e aos outros.

A experiência de Bruna, o modo como ela se ocupa consigo mesma, o modo como reflete sobre o gênero em sua vida e como cria suas próprias lições mostram que ela expõe, em suma, como a problematização que ela faz de si, enquanto lésbica, constitui uma estratégia de autoformação e/ou uma estratégia de reelaboração sobre si. A experiência de si, a Bruna, em relação ao gênero, confere a ela não apenas uma condição em que mostra como trabalha com o ver-se, mas como elabora ideias e comportamentos peculiares para agir em relação a si e aos outros. A experiência de Bruna constitui-se, assim, no modo como ela estabelece uma vinculação entre a relação do que viveu como lésbica e do que estabelece como sendo vital a uma pessoa. Bruna, portanto, usa suas experiências de vida como lésbica como um aprendizado e/ou um conhecimento para a vida. Usa esse conhecimento para agir no mundo, constituindo-se diferentemente a partir dessas experiências.

Em outro depoimento, Bruna expõe a significação que faz de si considerando os modos como era entendida/identificada/marcada por seus alunos,

tu consegue identificar quem é e quem não é, mesmo não dizendo nada, mesmo não falando nada, e, pra mim, é isso, passa pela materialidade do corpo, sim; agora, não me pergunta como exatamente isso acontece porque eu não sei, mas... quais são os sinais, quais são... e aí acho que é o conjunto da obra, é o que tu fala, como tu te porta, quais são tuas opiniões sobre determinada coisa. (Bruna, 2012)

Para Bruna, é pela materialidade do corpo, como um referente, que os alunos a viam como uma mulher "diferente". Como ela diz, é a partir do seu corpo, do modo como ela se porta e dá opiniões que era percebida pelos alunos, e é por essas marcas que era diferenciada em relação a outras mulheres. Mesmo não assumindo a sua lesbianidade na escola, Bruna relata que se sentia questionada em relação a seu corpo e seu modo de agir. Em outro momento da entrevista, conta que por diversas vezes foi questionada pelo seu jeito de falar e vestir-se. Como Bruna diz, os alunos deixavam transparecer nas falas as dúvidas e as incertezas que tinham em relação ao que ela realmente era. A verdade é que os discursos dos alunos conseguiam captar as diferenças na materialidade do corpo e no comportamento de Bruna em relação ao padrão de mulher, e por isso ela era questionada, mas não conseguiam explicar e/ou distinguir, pela linguagem, o que representava o seu corpo. Isso se dá, segundo Butler (2007), porque não há uma matriz de gênero, uma matriz ontológica que explique a verdade dos sujeitos. $O$ que há são tentativas de incorporar o gênero em uma perspectiva que naturaliza o sexo. Essas tentativas são sempre falhas e fraturadas, portanto há o que se pode chamar de oposições, ou seja, falhas dentro dos termos, rupturas que mostram como os termos são culturalmente produzidos (Butler,2007).

A materialidade dos corpos tem um peso na vida de todas as entrevistadas. Bruna salientou que sabia que a sua posição e o seu estilo causavam dúvidas a seus alunos. Porém, segundo ela, não faz isso, na escola, propositalmente, mas consequentemente, já que percebia que o seu corpo causava questionamentos às noções de normatividade sexual. 
Para Alice, outra professora entrevistada, a problematização do gênero surgiu em uma situação que, segundo ela, aconteceu em sala de aula, com dois alunos gays. Foi um caso entre ela e dois alunos de uma escola da rede pública. Diz ela:

foi um menino que uma vez me perguntou, ficou pra falar comigo no fim da aula e perguntou assim: "professora, acontece o seguinte, eu tenho que botar aparelho e eu fui no meu dentista e aí ele me deu várias cores de aparelho pra escolher e a cor que eu mais gostei foi o rosa, foi cor-de-rosa, mas eu não sei se eu me animo a botar um aparelho cor-de-rosa. (Alice, 2012)

Alice, como lembra, disse a ele que, se usasse a cor rosa no aparelho, talvez fossem mexer com ele e que o importante era ele pensar quanto isso poderia frustrá-lo ou não, quanto ele ia deixar esse fato incomodá-lo. Recordou que disse ao aluno que cada um deve usar a cor de que gosta e rememora que terminou falando:

agora eu quero te dizer uma coisa, eu sempre admirei muito, até hoje, eu sempre admiro muito mesmo, porque é presente mesmo quando eu vejo um homem de cor-de-rosa, admiro tanto... E uma semana depois ele foi de aparelho cor-de-rosa pra aula [risos]. (Alice, 2012)

Ela considera, portanto, a atitude do menino uma possibilidade de aproximação, de troca e de aceitação. $\mathrm{O}$ fato é que, para a professora Alice, esse aluno teve espaço para falar sobre o que é menosprezado e ignorado pelos discursos e pela linguagem da sexualidade no campo curricular e pedagógico porque ele identificou nela algo que os aproximava.

É importante frisar que ter com quem dividir as mesmas preocupações e interesses, ter com quem dividir sentimentos e emoções, no território escolar, para os gays e para as lésbicas, não é uma experiência comum. No currículo não há receptividade para a vida e as histórias daqueles que são considerados homossexuais ou transexuais. Por isso, Alice diz ter ficado feliz em pensar que aquilo que ela disse pode tê-lo ajudado:

A tomar aquela decisão que não foi fácil, achei bacana, e esse é um menino que eu vejo na rua, hoje, de mão com outros meninos, esse é um menino que se assumiu gay. $\mathrm{O}$ outro eu não vi, nunca mais encontrei, não sei o que é feito dele, e o outro, quando era, assim, xingado de gay, porque tudo era xingo, e ele ficava muito puto da cara, ele ficava muito puto da cara, ele ficava furioso, ficava louco e saía brigando com todo o mundo, ele se bancava também. (Alice, 2012)

Quando Alice relata que o aluno gay a procurou porque via nela uma condição de segurança e possiblidade de acolhimento do gênero, que ela não assumia publicamente, mas que ele percebia, e quando Bruna relata que o gênero a conduz a um modo de pensar e ver o mundo, percebemos que ambas indicam que há experiências de gênero acontecendo nos currículos escolares. Há uma ressignificação das experiências que elas viveram como lésbicas em suas ações como professoras. Bruna e Alice traduzem suas experiências de gênero, traduzem os perigos, as aventuras e os atravessamentos do gênero para as suas noções de vida. Traduzem o vivido e o sofrido em algo apreendido, 
em algo acumulado e produzido (Larrosa, 1994). O que elas fazem de suas experiências como mulheres que viveram a homossexualidade é usá-las como base para uma ascese, ou seja, para pensar, a partir da singularização nos modos como elas se relacionam com o mundo e com os outros, como devem agir em relação a seus alunos, por exemplo. O que fazem é estabelecer uma relação pedagógica em que uma de suas bases é constituída na singularidade das experiências de vida como lésbicas. A vida lésbica, assim, é, para elas, um campo de saber. Um campo do qual retiram algumas verdades e regras de conduta para consigo e para com os outros.

Para Ana Paula, professora entrevistada, a condição para que alguns temas sejam trabalhados na escola, como gênero e sexualidade, acontece se as professoras são “tocadas" por eles. Ou seja, para ela, o fato de ser lésbica está extremamente ligado ao ato de querer trabalhar pedagogicamente os temas da sexualidade na escola. E isso acontece, segundo ela, porque foi “tocada”, quer dizer, porque foi transformada pelas diversas experiências em relação ao gênero em sua vida. Ana Paula foi uma professora que relatou em sua entrevista várias situações de lesbofobia desde a infância até a vida adulta, principalmente nas instituições educacionais. Foi uma menina que teve de enfrentar os colegas chamando-a de "machorra" nas escolas onde estudava, mesmo não sendo lésbica, segundo ela, mas porque não se adequava aos estereótipos femininos. Teve de enfrentar, também, como lésbica, sérios conflitos nas escolas onde atuava como professora. Ana Paula, assim, tem a escola como um lugar de hostilidade para os gays e lésbicas e, exatamente por conhecer bem essas situações, diz que faz seu trabalho de ativismo e militância em relação ao sexo e ao gênero nos ambientes escolares.

Sílvia, apesar de discordar do argumento de Ana Paula, pois diz que nem todas as professoras lésbicas, por serem homossexuais ou bissexuais, problematizam o gênero nas escolas, também salienta que concorda com a ideia de que há aquelas, como ela, que são um "esteio" da discussão. Então, para ela, há as professoras lésbicas que não querem assumir essa tarefa por diferentes motivos e que precisam ser respeitadas por suas escolhas, e há aquelas, como ela, que "não basta ser, tem que discutir". Para Sílvia e Ana Paula, a experiência de gênero é uma causa, um compromisso de vida. É pelo gênero, e não apenas por ele, claro, que elas tencionam suas ações, que buscam questionar os sentidos e as circunstâncias do mundo. As experiências de gênero, assim, são um percurso pelo qual elas transformam a si e ao mundo. É também por essas experiências que essas professoras tentam instaurar mudanças na cultura e na sociedade. A partir de suas experiências de gênero, vão abrindo novos espaços e novos modos de pensar na esfera do pessoal e profissional. A lesbianidade ou a homossexualidade fazem parte do conjunto de elementos que as impulsiona como mulheres e professoras.

O currículo, portanto, não fica imune às ações e aos modos de pensar subjetivos dessas professoras. Mesmo que não tenham visibilidade nas escolas, não há como negar que elas criam, ao usar suas biografias e reflexões como lésbicas, uma subjetividade na qual o gênero produz efeitos na docência e nos currículos. Nessa direção, podemos afirmar que elas entrelaçam suas experiências como mulheres e lésbicas às vivências cotidianas de professoras. Mesmo não se assumindo como lésbicas, elas usam as experiências de vida para problematizar os códigos e a regras/normas sexuais vigentes. Elas usam as experiências com o corpo para se relacionarem consigo e com o 
mundo. As suas experiências de gênero são, para elas, um sentido que lhes possibilita a construção e o domínio sobre si e sobre suas práticas como professoras.

No que tange ao esforço e à capacidade de Sílvia para interferir no modo como as pessoas pensam as relações, vale citar uma de suas falas, na qual ela narra algumas reflexões que faz usando o conceito de resiliência para indicar como torna suas experiências de gênero uma aprendizagem "positiva", ou seja, algo que leva para a sua vida. De acordo com Sílvia, o fato de ser lésbica impõe uma decisão para não se tornar uma pessoa rancorosa ou com estima baixa:

pode buscar fazer da tua vida coisas que não sejam positivas, ou tu pode, através dessa situação, de te reconhecer enquanto lésbica, fazer disso a construção positiva da tua vida. (Sílvia, 2012)

Sílvia corajosamente, portanto, recusa a primeira opção. Ela não se conforma com os discursos de gênero que poderiam deixá-la "rancorosa" ou com "baixa estima". O que ela faz é o contrário. Ela tenta sair dos discursos da zona de dificuldade para os discursos que transformam a adversidade em algo positivo. Sílvia, assim como Ana Paula, não aceita a noção de verdade atribuída, por uma visão homofóbica, à homossexualidade, não aceita o olhar dramático dado às práticas homossexuais e não aceita os discursos que naturalizam o gênero. Como já observamos, elas, a partir de suas experiências de gênero, não apenas negam os discursos negativos como também tentam transformar esses discursos que inferiorizam, excluem e negam a vida e a cultura lésbica, em discursos que valorizam essa mesma cultura. A partir de si, criam estratégias, e não apenas uma prática, para construir como professoras outras relações e discursos nos quais a ordem do humano ganha visibilidade e valorização. E elas fazem esse trabalho não apenas em si e por si, mas também nos outros e pelos outros.

A experiência de Sílvia e Ana Paula é algo, portanto, que Gabriela e Ana Maria, duas outras professoras pesquisadas que abandonaram a escola por conta da homofobia, ainda querem construir. Isso se dá porque elas entendem que aquilo que viveram como experiência de gênero, como professoras, no passado, foi traumático diante das imposições e retaliações que sofreram no momento em que atuaram como docentes. Ambas saíram da escola porque passaram por situações de conflito em relação ao gênero. Por conta dessas circunstâncias, ambas deixaram a escola sem dizer e resolver o que desejavam, ambas seguiram sem dizer o que pensavam, o que as levou a uma profunda desilusão em relação à escola. Ambas, assim, têm o mesmo sentimento de querer retomar a vida como docentes. Não apenas voltar, mas voltar para mudar, para transformar o que foi negativo. Gabriela diz que não quer reduzir sua trajetória ao momento negativo que teve de enfrentar como professora e lésbica. Não quer vincular sua trajetória à situação constrangedora que a levou a sair da escola. Gabriela diz querer refazer essa trajetória como docente. Quer usar a "falta de experiências de gênero" que diz ter tido em algo que contribua para seus novos projetos como professora.

Ana Maria também quer reverter sua história como professora. Hoje, ela diz que se sente mais forte, que possivelmente faria diferente. Não faria diferente somente por uma questão de coragem, mas de tranquilidade para falar as coisas da maneira como ela pensa: 
$\mathrm{Na}$ época eu não tinha vergonha nenhuma, sabe, só que eu não tava preparada pra fazer esse enfrentamento, aquela discussão ali, sabe. (Ana Maria, 2012)

Hoje, então, ela diz que quer voltar a trabalhar como professora nas escolas, que quer e pode ir contra o "velho hábito reprodutor" (Ana Maria, 2012) da escola quando esta fala de sexualidade. Ana Maria quer refazer a sua história como docente produzindo efeitos de questionamento e subversão na definição normativa da sexualidade e do próprio corpo nas escolas, quer reinventar a si como professora. E essa mudança ela não deseja apenas para si, mas também para os outros. Ana Maria quer praticar o cuidado de si na escola, quer convidar os alunos a pensarem sobre si, a reinventarem a si e a suas subjetividades pensando no gênero, quer abrir espaços para essas experiências nas escolas. Ela quer, assim, como Sílvia e Ana Paula fazem, elevar a sua autoestima como professora e lésbica nas instituições educativas.

\section{CONSIDERAÇÕES FINAIS}

Para iniciar, gostaríamos de lembrar que o texto, de modo geral, quis contribuir para a visibilidade das mulheres lésbicas na educação. De certo modo, tem como intenção criticar a marginalização e a invisibilidade das análises da homossexualidade feminina nos estudos no campo da pedagogia.

Considerando esse comentário mais geral, destacamos que o principal desafio deste trabalho foi encontrar rastros de como estão sendo produzidas outras pedagogias nas escolas, em proximidade com um currículo queer, tomando como base os discursos das experiências docentes das professoras lésbicas. E, consequentemente, pensar em como a desconstrução da normalização das identidades sexuais vem ressignificando a própria subjetividade docente. Nossa proposição foi desenvolver uma reflexão para o currículo pela narrativa das professoras lésbicas. Para isso, buscamos elementos que pudessem dizer como as professoras criavam suas próprias estratégias e modos de existir na docência tomando como base os discursos e suas experiências de gênero e sexualidade.

Com isso podemos apontar alguns indícios do modo como uma pedagogia queer vai sendo construída no cotidiano escolar e como o gênero vai sendo desconstruído e reconstruído na relação dos sujeitos com as tecnologias discursivas. Sem dúvida, o modo de olhar o mundo por quem é "achacada", da professora Bruna; a troca de afeições e conselhos, por exemplo, da professora Alice e seu aluno gay; a reafirmação da identidade lésbica na escola e o ativismo militante das professoras Ana Paula e Sílvia; a revisão e a crítica das próprias condutas como mulheres e lésbicas nas escolas, das professoras Ana Maria e Gabriela, permitiram-nos evidenciar que as experiências de gênero e sexualidade das professoras perpassam o currículo e a pedagogia na escola não pela simples adição de conteúdos gays, lésbicos e transexuais nos currículos escolares, mas pelas relações e problematizações que estas professoras criam a partir da materialidade de seus corpos, de suas formas de colocar-se no mundo e, por vezes, de assumir politicamente a condição lésbica como possibilidade de vida para si mesmas e para os alunos.

Pensar a professora lésbica na sala de aula foi, portanto, estratégico para desnaturalizar os cenários heterossexuais da docência e do currículo. Apesar de tímidos, 
pode-se dizer que os discursos de gênero, da lesbianidade, citados aqui, permitiram apontar como as professoras pesquisadas contribuíram para a desnaturalização da identidade sexual na sala de aula, por exemplo, pela desmistificação da estabilidade da relação causal entre sexo e identidade de gênero que a materialidade de seus corpos causaram; pela referência que elas representaram para aqueles estudantes que não se encaixam nos estereótipos homem/mulher, hétero/homo; e pela luta que elas travam politicamente pelo fim da discriminação de gênero nas escolas.

Há muito já se sabe da importância que a história de vida e a experiência pessoal de um/a professor/a têm na constituição da docência, dos saberes docentes e de um estilo próprio de ser professor/a (Nóvoa, 1992; Tardif, 2002). A materialidade dos corpos e do desejo marca a vida das professoras investigadas e suas histórias profissionais, instituindo ambiguidades, incertezas, confusões e possibilidades em relação às normas identitárias. Ainda que elas não o façam de modo intencional ou sistemático, quando essas normas são questionadas pela presença do corpo, afetos e desejos "estranhos", tensões, conflitos e exclusões são gerados, atingindo esses sujeitos, muitas vezes de forma cruel. Mas também esses mesmos acontecimentos geram dúvidas, empatia, solidariedades e identificações inesperadas que possibilitam outras formas de conhecimento e existência. Nesses acontecimentos estão os indícios de uma pedagogia e de um currículo queer que necessitam de ser provocados e ampliados de modo intencional com a finalidade de romper os sistemas binários e pensar e admitir os gêneros, a sexualidade e os corpos plurais, múltiplos e em transformação.

A teoria queer e os estudos feministas têm a relevância de indicar que o gênero e o sexo são formas primárias de experiência do poder entre os seres humanos, e as definições hegemônicas desses constructos fundamentam as práticas pedagógicas. A crítica à oposição heterosexual/homosexual, uma categoria que certamente organiza as práticas sociais e as normativas do trabalho escolar e do currículo, é o foco de uma política queer e de práticas pedagógicas que se movem no sentido de evidenciar essas categorias como mutuamente constitutivas e não excludentes. Como destaca Louro (2001), uma pedagogia e um currículo queer estariam centralmente empenhados em produzir diferenças e trabalhar com a precariedade de todas as identidades, tendo consequências epistemológicas importantes para o trabalho docente e os currículos.

As narrativas das professoras deixam claro que há uma pedagogia e/ou um currículo sendo produzido a partir da ruptura com a tradição do campo curricular em relação ao gênero e à sexualidade. Esse movimento não apenas subverte as normas dos comportamentos sexuais, como também cria uma situação política de reconfiguração dos estilos de pensar a vida e a própria educação. Observamos que, mesmo algumas professoras tendo sido oprimidas e sujeitadas pelo ódio e/ou pela lesbofobia, elas conseguem produzir e manter uma reativação positiva de sua vida e sexualidades. É na convivência e nos laços de amizade com os homossexuais, por exemplo, e com os outros, que elas se reconfiguram, despistam as interdições e constroem liberdades. É a partir dessas experiências que elas constituem as oportunidades para traçar as linhas de fuga nos aparelhos institucionais. São esses elementos de resistência que reativam o modo de as professoras pensarem em si como educadoras, criando, assim, novas modalidades de viver o gênero e a educação. O que se percebe é que essas professoras, com suas experiências de gênero, constituem uma maquinaria subjetiva para conduzirem a si e aos outros. 
O que elas fazem é criar um estilo próprio de existência como professoras. $\mathrm{E}$ isso faz com que elas não se sintam totalmente controladas pelos aparelhos institucionais que tentam determinar um modo genereficado de viver o gênero e a docência.

O que essas professoras nos mostram é a docência como um campo de possibilidades. Um campo em que os sujeitos podem inventar uma cultura, em que podem induzir novas "modalidades de relações, modos de vida, tipos de valores, formas de troca entre indivíduos que sejam realmente novas, que não sejam homogêneas nem se sobreponham às formas culturais gerais" (Foucault, 2006, p. 122). Uma cultura que não seja direcionada apenas aos homossexuais, mas também aos heterossexuais, e a todos aqueles que entendem a importância do poder que há em tratar de si, dos seus saberes, da sua própria constituição e existência.

\section{REFERÊNCIAS}

Agamben, G. O que resta de Auschwitz: o arquivo e a testemunha. Tradução de Selvino J. Assmann. São Paulo: Boitempo, 2008.

Benjamin, W. O narrador. In: Benjamin, W.; Horkheimer, M.; Adorno, T. W.; Habermas, J. (Orgs.). Textos escolhidos. Tradução de José Lino Grünnewald. 7. ed. São Paulo: Abril Cultura, 1983. (Coleção Os Pensadores).

. Experiência e pobreza. In: . Magia e técnica, arte e politica. Tradução de Sérgio Paulo Rouanet. São Paulo: Brasiliense, 1996. (Obras Escolhidas, v. 1).

Butler, J. Corpos que pesam: sobre os limites discursivos do "sexo". In: Louro, G. L. (Org.). O corpo educado: pedagogias da sexualidade. Tradução de Tomaz Tadeu da Silva. 2. ed. Belo Horizonte: Autêntica, 2007. p. 151-172.

. Problemas de gênero: feminismo e subversão da identidade. Tradução de Renato Aguiar. 3. ed. Rio de Janeiro: Civilização Brasileira, 2010.

Foucault, M. A hermenêutica do sujeito. São Paulo: Martins Fontes, 2004.

. O triunfo social do prazer sexual: uma conversação com Michel Foucault. In: Мотта, M. B. (Org.). Ditos e escritos V: ética, sexualidade e política. Tradução de Elisa Monteiro e Inês A. D. Barbosa. 2. ed. Rio de Janeiro: Forense Universitária, 2006. p. 119-125.

Furlani, J. Sexos, sexualidades e gêneros: monstruosidades no currículo da educação sexual. Educação em Revista, Belo Horizonte: UFMG, n. 46, p. 269-285, dez. 2007.

Larrosa, J. Tecnologias do eu e educação. In: Silva, T.T. O sujeito da educação. Petrópolis: Vozes, 1994. p. 35-86.

. Experiencia (y alteridade) em educación. Buenos Aires: FLACSO, 2005.

. Pedagogia profana: danças, piruetas e mascaradas. 5. ed. Tradução de Alfredo Veiga-Neto. Belo Horizonte: Autêntica, 2010.

Lauretis, T. A tecnologia do gênero. In: Holanda, H. B. (Org.). Tendências e impasses: o feminismo como crítica da cultura. Rio de Janeiro: Rocco, 1994. p. 206-242.

Luhmann, S. Queering/querying Pedagogy? Or, Pedagogy is a pretty queer thing. In: Pinar,W.F. (Org.). Queer theory in education. New Jersey; Londres: Lawrence Erlbaum Associates Publishers, 1998. p. 141-156. 
Louro, G. Teoria queer - uma política pós-identitária para a educação. Estudos Feministas, Florianópolis: UFSC, ano 9, 2º sem., p. 541-553, 2001.

. Um corpo estranho: ensaios sobre a sexualidade e teoria queer. 1 . ed. Belo Horizonte: Autêntica, 2008.

Maciel, P. D. Lésbicas e professoras: modos de viver o gênero na docência. 2014.178p. Tese (Doutorado em Educação) - Universidade Federal de Pelotas, Pelotas, 2014.

Nicholson, L. Interpretando o gênero. Estudos Feministas, Florianópolis: UFSC, v. 8, n. 2, p. 9-41, 2000.

NóvoA, A. Vidas de professores. Porto: Porto Editora, 1992.

Preciado, B. Cuerpo y discurso em la obra de Judith Butler: políticas de lo abyecto. In: Cordoba, D.; SÁez, J.; Vidarte, P. (Orgs.). Teoría queer: políticas bolleras, maricas, trans, mestizas. Madrid: Editorial Egales, 2005. p. 111-132.

. O manifesto contrassexual. Tradução de Maria Paula Gurgel Ribeiro. São Paulo: n-1 Edições, 2014.

Reis, C.; Paraíso, M. A. Normas de gênero em um currículo escolar: a produção dicotômica de corpos e posições de sujeito meninos-alunos. Estudos Feministas, Florianópolis: UFSC, v. 22, n. 1, p. 237-256, jan./abr. 2014.

Rich, A. Heterossexualidade compulsória e existência lésbica. Tradução de Carlos Guilherme do Valle. Revista Bagoas, Natal: UFRN, n. 5, p. 17-44, 2010.

Sedgwick, E. K. Epistemology of the closet. Berkeley: University of Califórnia Press, 1990. TARdif, M. Saberes docentes E formação profissional. Petrópolis: Vozes, 2002.

Vianna, C.; Unbehaum, S. Gênero na educação básica: Quem se importa? Uma análise de documentos de políticas públicas no Brasil. Educação E' Sociedade, Campinas: CEDES, v. 27, n. 95, p. 407-428, maio/ago. 2006.

\section{SOBRE AS AUTORAS}

Patrícia Daniela Maciel é doutora em educação pela Universidade Federal de Pelotas (UFPel). Professora do Instituto Federal do Paraná (IFPR). E-mail: sissahmaciel@gmail.com

Maria Manuela Alves Garcia é doutora em educação pela Universidade Federal do Rio Grande do Sul (UFRGS). Professora da Universidade Federal de Pelotas (UFPel). E-mail: garciamariamanuela@gmail.com 